\title{
Emergency Percutaneous Transluminal Coronary Angioplasty During Acute Myocardial Infarction for Patients More Than 70 Years of Age
}

\author{
Kurt J. Holland, MD, William W. O'Neill, MD, Eric R. Bates, MD, Bertram Pitt, MD, \\ and Eric J. Topol, MD
}

\begin{abstract}
Thirty-five patients $>70$ years of age with acute myocardial infarction (AMI) were treated with emergency percutaneous transluminal coronary angioplasty (PTCA). Seventeen (49\%) patients received previous thrombolytic therapy: streptokinase (10 patients), tissue plasminogen activator (6) and combined tissue plasminogen activator and urokinase (1). Infarct-related artery patency was achieved in 26 patients $(\mathbf{7 4} \%)$ after PTCA. Total in-hospital mortality was $34 \%$. Univariate analysis showed a higher in-hospital mortality in patients with an occluded vessel after PTCA (78\%) than in those patients with a patent infarct-related artery $(19 \%)(p=0.003)$. Symptomatic coronary reocclusion occurred in 3 patients (15\%) during the hospital stay. Compared with emergency PTCA in 200 consecutively treated patients $<\mathbf{7 0}$ years of age, the in-hospital mortality was increased (34 vs $6 \%$, $p<0.001$ ), and the primary success rate was reduced (66 vs $90 \%$, p <0.001). At a mean follow-up of 28 months, there has been a $13 \%$ out-of-hospital mortality rate in the elderly patients ( 3 patients died). Of the 20 surviving patients, 14 are asymptomatic and 6 have class II angina. In conclusion, emergency PTCA for AMI in elderly patients is associated with a decreased success rate and a higher mortality rate. However, the in-hospital mortality rate is not dissimilar to that in elderly AMI patients treated with conventional therapy or thrombolytic therapy alone, and the postdischarge mortality rates are low.
\end{abstract}

(Am J Cardiol 1989;63:399-403)

From the Division of Cardiology, Department of Internal Medicine, University of Michigan Medical Center, Ann Arbor, Michigan. Manuscript received July 25, 1988; revised manuscript received and accepted November 4, 1988

Address for reprints: Eric J. Topol, MD, Division of Cardiology, University of Michigan Medical Center, B1 F245, 1500 East Medical Center Drive, Ann Arbor, Michigan 48109-0022.
B efore the era of reperfusion, a number of studies in the 1960 s and 1970 s showed a 30 to $50 \%$ in-hospital mortality rate for patients older than 70 years of age with acute myocardial infarction (AMI).,2 While thrombolytic therapy has been shown to reduce mortality in younger patients, it has been less efficacious in older patients. ${ }^{3,4}$ In the Gruppo Italiano per lo Studio della Streptochinasi nell'Infarto Miocardico (GISSI) randomized trial of intravenous streptokinase, there was no apparent mortality reduction in the elderly subset of patients. ${ }^{3}$ Moreover, Lew et $\mathrm{al}^{4}$ found that patients 75 years or older had a 10 -fold higher in-hospital mortality rate and 1 -year mortality rate than patients $<75$ years of age after treatment with intravenous streptokinase. Recently, percutaneous transluminal coronary angioplasty (PTCA) has emerged as a new intervention for reperfusion during AMI. Limited data exist regarding the efficacy of PTCA in the elderly. The present pilot study defines the clinical outcomes, technical success rate and morbidity and mortality of emergency PTCA for patients $>70$ years of age with AMI, and compares these results with those in patients $<70$ years of age similarly treated.

\section{METHODS}

Study patients: At our institution, all patients with cvidence of AMI and fulfillment of predefined criteria from January 1984 to December 1986 were taken to the cardiac catheterization laboratory on an emergency basis. Criteria for acute catheterization were: (1) presence of chest pain consistent with AMI; (2) electrocardiographic evidence of AMI as indicated by $\geq 1 \mathrm{~mm}$ ST elevation or depression in 2 consecutive leads; and (3) $<6$ hours since onset of chest pain or persistent pain after 6 hours. Forty-nine patients $\geq 70$ years of age had emergency cardiac catheterization for AMI. Thirty-five of these patients had acute PTCA performed and they comprise the study group. PTCA was not performed in 14 patients. Eight patients had a patent vessel and severe, multiple vessel coronary disease and they underwent coronary artery bypass surgery. Four patients had evidence of extensive angiographic filling defect(s) and received intracoronary thrombolytic therapy. Two patients had a diffusely diseased infarct vessel and were believed to be unsuitable for PTCA. The comparison group consisted of 200 consecutive patients with AMI $<70$ years of age who were concurrently treated with PTCA from May until December 1986. No patient was 


\begin{tabular}{|c|c|c|c|c|c|c|c|c|c|c|c|c|}
\hline $\begin{array}{l}\text { Pt. } \\
\text { No. }\end{array}$ & $\begin{array}{l}\text { Age } \\
\text { (yrs), Sex }\end{array}$ & $\begin{array}{l}\text { Systolic } \\
\text { BP } \\
(\mathrm{mm} \mathrm{Hg})\end{array}$ & $\begin{array}{l}\text { Kıllıp } \\
\text { Class }\end{array}$ & IRCA & $\begin{array}{l}\text { Diseased } \\
\text { Vessels } \\
\text { (n) }\end{array}$ & $\begin{array}{l}E F \\
(\%)\end{array}$ & $\begin{array}{l}\text { LVEDP } \\
(\mathrm{mm} \mathrm{Hg})\end{array}$ & $\begin{array}{l}\text { Lytic } \\
\text { Therapy }\end{array}$ & $\begin{array}{l}\text { PTCA } \\
\text { Outcome }\end{array}$ & $\begin{array}{l}\text { Peak } \\
\text { CK } \\
\text { (IU/liter) }\end{array}$ & $\begin{array}{l}\text { Time to } \\
\text { PTCA } \\
\text { (hrs) }\end{array}$ & $\begin{array}{l}\text { Clinical } \\
\text { Outcome }\end{array}$ \\
\hline 1 & $74, \mathrm{M}$ & 112 & 1 & LAD & 3 & 22 & 35 & 0 & P. Success & 11,200 & 9 & Died \\
\hline 2 & $70, \mathrm{~F}$ & 135 & 1 & $\mathrm{R}$ & 1 & 62 & 25 & 0 & Success & 288 & 4 & Survived \\
\hline 3 & $74, M$ & 110 & 1 & $\mathrm{R}$ & 3 & 39 & 12 & IC SK & Success & 1,536 & 7 & Survived \\
\hline 4 & $78, F$ & 130 & IV & LC & 1 & 53 & 18 & 0 & Failure & 426 & 8 & Survived \\
\hline 5 & $74, M$ & 86 & III & LAD & 1 & - & 15 & IC SK & Fallure & 8,160 & 4 & Died \\
\hline 6 & $81, \mathrm{M}$ & 125 & I & LAD & 3 & - & - & 0 & Vessel occl. & - & 4 & Died \\
\hline 7 & $74, \mathrm{M}$ & 110 & I & $\mathrm{R}$ & 3 & 45 & 16 & 0 & Failure & 1,040 & 3 & Survived \\
\hline 8 & $72, F$ & 135 & II & $\mathrm{R}$ & 2 & 69 & 20 & 0 & Success & 2,061 & 5 & Survived \\
\hline 9 & $71, \mathrm{M}$ & 122 & 1 & $R$ & 3 & 47 & 20 & 0 & P. Success & 2,135 & 4 & Survived \\
\hline 10 & $80, F$ & 144 & ॥ & LAD & 2 & - & - & 0 & Success & 482 & 3 & Survived \\
\hline 11 & $71, F$ & 158 & I & $\mathrm{R}$ & 3 & 71 & 30 & IV SK & P. Success & 1,266 & 6 & Died \\
\hline 12 & $71, M$ & 115 & II & $\mathrm{R}$ & 1 & 47 & 16 & IV SK & Success & 1,395 & 3 & Survived \\
\hline 13 & $72, F$ & 90 & IV & LAD & 3 & 28 & 30 & 0 & P. Success & 6,900 & 6 & Survived \\
\hline 14 & $77, \mathrm{M}$ & 130 & $\|$ & $\mathrm{R}$ & 1 & 55 & 20 & 0 & Vessel occl. & - & 3 & Died \\
\hline 15 & $71, M$ & 180 & 1 & $\mathrm{R}$ & 2 & 42 & 12 & 0 & Success & 2,060 & 6 & Survived \\
\hline 16 & $72, M$ & 130 & 1 & LAD & 1 & 27 & 30 & IV SK & Success & 323 & 8 & Survived \\
\hline 17 & $70, M$ & 94 & $i$ & $\mathrm{R}$ & 1 & 55 & 15 & IV SK & Vessel occl. & 2,400 & 4 & Survived \\
\hline 18 & $70, F$ & 60 & IV & LAD & 3 & - & - & 0 & Fallure & 3,786 & 15 & Died \\
\hline 19 & $70, M$ & 100 & II & LAD & 1 & 41 & 36 & 0 & Fallure & 3,960 & 14 & Died \\
\hline 20 & $75, M$ & 80 & IV & $\mathrm{R}$ & 2 & - & 32 & IV SK & Success & - & 3 & Died \\
\hline 21 & $73, F$ & 100 & II & LC & 3 & 35 & 15 & IC SK & Success & 972 & 4 & Survived \\
\hline 22 & $73, M$ & 130 & 1 & LAD & 1 & 47 & 26 & $t-P A$ & Success & 5,120 & 6 & Died \\
\hline 23 & $73, M$ & 150 & II & LAD & 3 & 25 & 28 & IV SK & Failure & 4,140 & 10 & Survived \\
\hline 24 & $91, \mathrm{~F}$ & 100 & ॥ & LAD & 3 & - & - & 0 & Failure & - & 2 & Died \\
\hline 25 & $70, M$ & 110 & I & LAD & 1 & 58 & 17 & $t-P A$ & Vessel occl. & - & 4 & Survived \\
\hline 26 & $70, M$ & 130 & 1 & $\mathbf{R}$ & 1 & 52 & 26 & $t-P A$ & Success & 3,540 & 5 & Survived \\
\hline 27 & $76, \mathrm{~F}$ & 85 & IV & LC & 3 & - & 32 & 0 & Success & 12,120 & 4 & Died \\
\hline 28 & $75, F$ & 80 & IV & LAD & 3 & 18 & 39 & 0 & Failure & 1,645 & 6 & Died \\
\hline 29 & $70, M$ & 120 & 1 & $\mathbf{R}$ & 2 & 61 & 24 & $t-P A$ & Success & 519 & 3 & Survived \\
\hline 30 & $76, M$ & 140 & III & LAD & 3 & 64 & 24 & $t-P A$ & Success & 2,630 & 6 & Survived \\
\hline 31 & $78, M$ & 95 & 1 & $\mathrm{R}$ & 3 & 40 & 21 & 0 & P. Succcss & 703 & 4 & Survived \\
\hline 32 & $72, M$ & 102 & 1 & $\mathrm{R}$ & 3 & 73 & 14 & t-PA & P. Success & 2,120 & 6 & Survived \\
\hline 33 & $70, M$ & 103 & $i$ & LC & 1 & 77 & 11 & IV SK & Success & 530 & 4 & Survived \\
\hline 34 & $82, \mathrm{M}$ & 98 & I & $\mathrm{R}$ & 3 & 60 & 24 & 0 & P. Success & - & 3 & Survived \\
\hline 35 & $74, M$ & 120 & 1 & LAD & 1 & 48 & 38 & $\mathrm{t}-\mathrm{PA}+\mathrm{UK}$ & P. Success & 5,580 & 6 & Survived \\
\hline
\end{tabular}

excluded from the study because of age or presence of cardiogenic shock. Cardiogenic shock was defined as systolic blood pressure $<80 \mathrm{~mm} \mathrm{Hg}$ that was unresponsive to volume expansion.

Coronary angioplasty protocol: In the emergency room, 15 patients received thrombolytic therapy and all patients received sublingual or intravenous nitroglycerin and morphine sulfate for pain. Patients were then transferred directly to the cardiac catheterization laboratory. The cardiac catheterization laboratory team was on call 24 hours a day and the operators had performed more than 200 elective and at least 50 emergency PTCA procedures.

Vascular access was obtained through the femoral artcry. Intravenous heparin was administered: 5,000 U in patients receiving thrombolytic therapy and $10,000 \mathrm{U}$ in the other patients. Arteriography of the infarct-related vessel was performed first, followed by arteriography of the uninvolved vessel. Left ventriculography was performed in patients who were sufficiently stable to undergo the procedure safely. PTCA was then performed in patients when clinically indicated. All patients received intravenous heparin for a minimum of 24 hours after PTCA. Total creatine kinase and isoenzymes were measured in all patients.

Follow-up: After PTCA, all patients were treated with aspirin, $325 \mathrm{mg}$ a day, and a calcium antagonist. An attempt to perform coronary arteriography was made before discharge. Telephone follow-up was obtained at 6-month intervals.

\section{RESULTS}

Forty-nine patients $>70$ years of age with AMI presented between January 1984 and December 1986. PTCA was performed in 35 patients and they comprise the study population. The reasons for not performing PTCA in the other 14 patients were provided in the Methods section. Seventeen patients $(49 \%)$ were trcated with thrombolytic therapy before emergency PTCA. Eight patients received intravenous streptokinase, 2 intracoronary streptokinase, 6 intravenous tissue plasminogen activation and 1 patient combined intravenous tissue plasminogen activator and urokinase.

Demographic characteristics of the patient population are listed in Table I. Of note, most patients presented to the catheterization laboratory and had PTCA per- 
formed within 6 hours from the onset of chest pain. Seven patients (20\%) had PTCA performed after 6 hours from symptom onset. Eight patients (23\%) had PTCA performed within 3 hours of the onset of chest pain. Seventeen patients (49\%) received thrombolytic therapy before PTCA. Upon presentation to the catheterization laboratory, the mean systolic blood pressure was $117 \pm$ $24 \mathrm{~mm} \mathrm{Hg}$. Eight patients were in Killip class III or IV at presentation and the mean Killip class was $1.9 \pm 1.1$. Six patients $(18 \%)$ were in cardiogenic shock before catheterization. All patients had admission history, electrocardiographic changes and subsequent enzymatic evidence confirming the diagnosis of AMI. Thirty-two patients had ST elevation and 3 patients had marked anterior ST depression, with prominent $\mathrm{R}$ waves suggesting posterior wall infarction. Electrocardiographic changes had an anterior distribution in 17 patients (49\%) and an inferior or lateral distribution in 18 patients $(51 \%)$.

Catheterization results: Cardiac catheterization was performed and the infarct artery was identified in all patients. The infarct vessel was the left anterior descending in 15 patients, the left circumflex in 4 and the right coronary artery in 16 patients. Before PTCA, the infarct artery was patent in 18 patients $(51 \%)$. The residual diameter stenosis in these 18 patients was $77 \pm$ $11 \%$. Of the 18 patients with a patent infarct-related vessel, 10 had received thrombolytic therapy, 1 achieved patency during baseline contrast injections and $7 \mathrm{pa}-$ tients had a patent artery without thrombolytic therapy before the coronary angiography.

As shown in Table I, most patients had multivessel coronary artery disease including 3-vessel disease in 17 patients (49\%). Twenty-eight patients had left ventriculugraphy performed and the mean ejection fraction was $48 \pm 16 \%$. The patients who did not have determination of left ventricular end-diastolic pressure or left ventriculography were hemodynamically unstable and represented patients with poor left ventricular function.

Technical results: Figure 1 shows the technical results of the acute coronary angioplasty. Of the $35 \mathrm{pa}-$ tients in the study population, $26(74 \%)$ had a patent artery following PTCA. Patency was achieved via PTCA in 23 patients for an overall recanalization success rate of $66 \%$. However, 15 patients had a postprocedural residual stenosis of $<50 \%$ but 8 patients had a postprocedural stenosis of $>50 \%$. In 2 . patients with a patent infarct vessel and high grade stenosis, there was failure to cross the lesion. In 1 patient, patency was maintained after abrupt closure with the use of an autoperfusion catheter. This patient subsequently underwent emergent bypass surgery.

Nine patients had an occluded infarct artery after PTCA. In 6 of 17 palients with an initially occluded vessel, the coronary angioplasty procedure failed to open the vessel. In 3 patients with an initially patent vessel, there was abrupt closure during the PTCA procedure with failure to regain patency.

The number of patients is too small to consider technical success by method(s) of reperfusion. Nonetheless, of the 17 patients who received thrombolytic therapy, 4 $(17 \%)$ died in the hospital compared with $8(44 \%)$ of 18 patients who were treated with PTCA alone $(\mathrm{p}=$ $0.193)$. Only $1(6 \%)$ of 17 patients receiving thrombolytic therapy developed cardiogenic shock during or af-

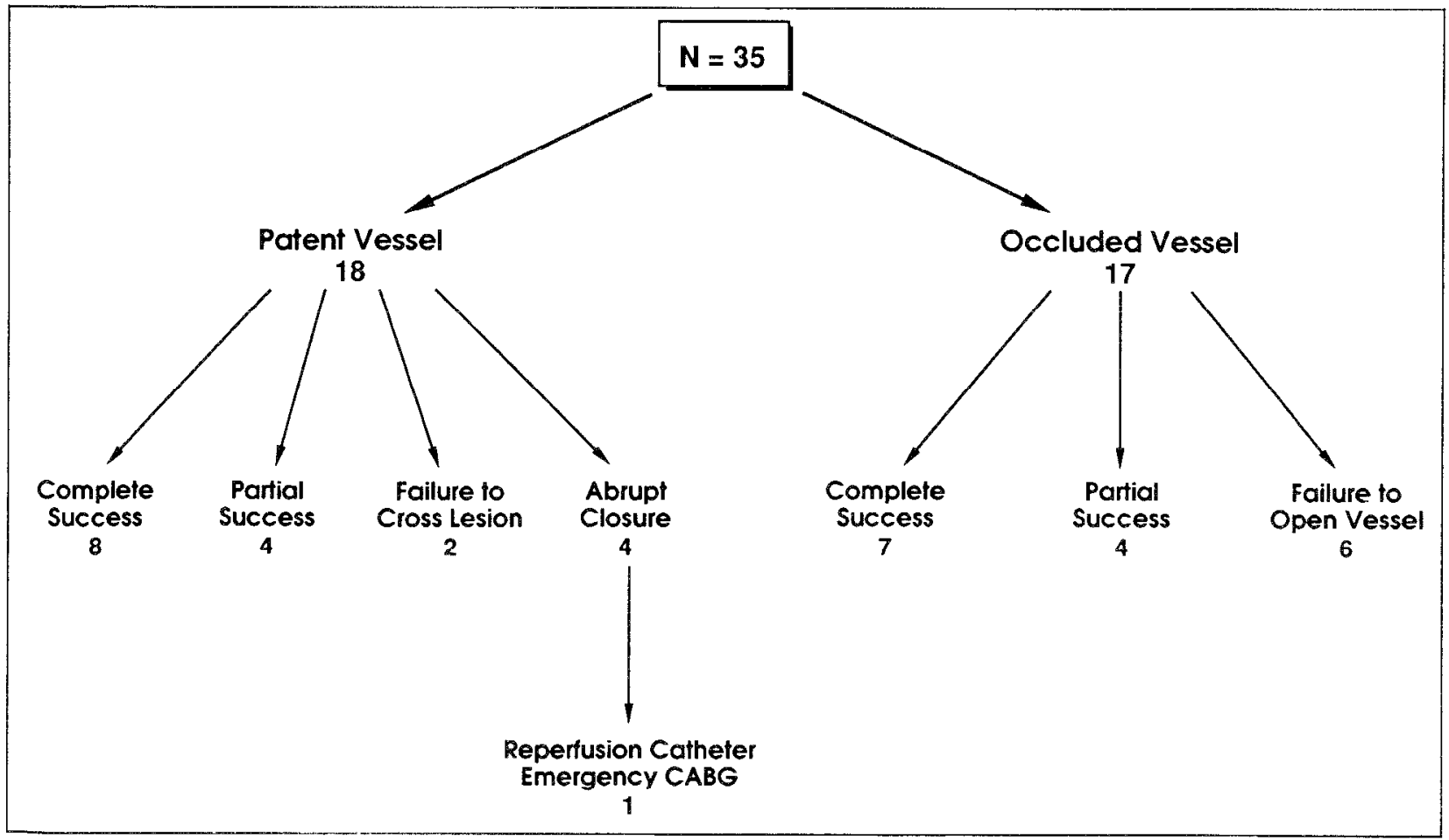

FIGURE 1. Technlcal results presented on basis of initial perfusion status of the infarct vessel. CABG = coronary artery bypass surgery. 
ter PTCA. Conversely, 5 (28\%) of 18 patients undergoing PTCA alone developed cardiogenic shock and all subsequently died $(p=0.086)$.

Clinical course: Four patients developed recurrent chest pain after PTCA suggestive of acute reocclusion and underwent emergency repeat coronary angiography. Three patients were found to have an occluded infarct vessel and 1 patient had restenosis but preserved flow. PTCA was successfully repeated in the patient with restenosis. In 2 patients, repeat PTCA failed to open the infarct-related vessel and in 1 patient repeat PTCA was not attempted.

Nine patients underwent bypass surgery during their hospital stay; 4 patients urgently within 24 hours of the acute catheterization and 5 patients electively within 7 to 10 days. Only 1 of these patients $(11 \%)$ subsequently died during the hospital course from refractory ventricular arrhythmia.

Mortality and morbidity: Twelve patients (34\%) died during their hospital stay. Ten patients died of cardiogenic shock and 2 of refractory arrhythmia. Six patients developed cardiogenic shock during or after the PTCA and all subsequently died. Four of the 6 patients presenting with cardiogenic shock died.

Four patients developed congestive heart failure, defined as rales half way up the posterior chest field requiring long-term diuretic therapy. Five patients had major peripheral vascular complications. Three patients required surgical repair of the femoral artery including 2 patients with femoral artery occlusion and 1 patient with an arteriovenous fistula. The 2 other patients had substantial blood loss ( $>2$ units of blood) from the periaccess site.

Predictors of in-hospital mortality: Univariate analysis was performed with a number of variables in an attempt to predict mortality in this group of elderly patients undergoing emergency PTCA. Cardiogenic shock on presentation, age $>75$ years and anterior AMI had a trend of an increased mortality. Importantly, the 9 patients with an occluded vessel after coronary angioplasty had a $78 \%$ in-hospital mortality rate; this was significantly higher than those 26 patients with a patent vessel whose mortality rate was $19 \%(\mathrm{p}=0.003)$. No other variable was found to be predictive of mortality.

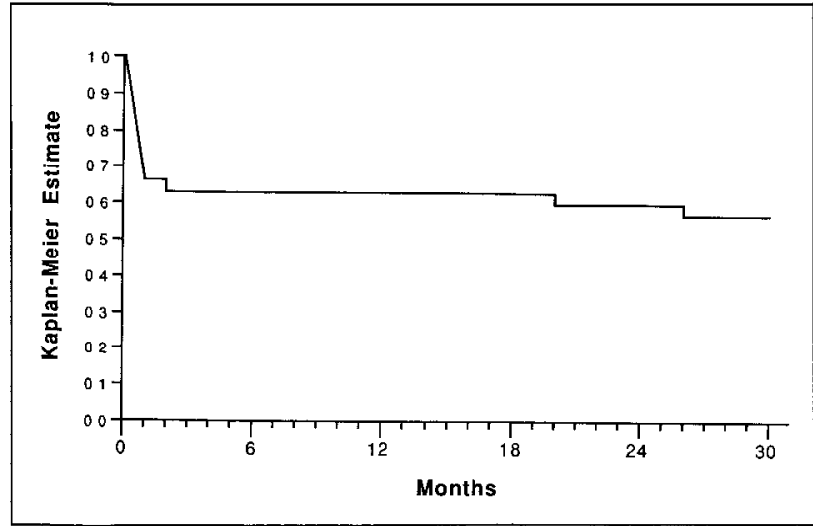

FIGURE 2. Survival analysis of the study group of 35 patients.
Comparison with younger patients: These PTCA results in the elderly were compared with a group of 200 consecutive patients $<70$ years of age with AMI similarly treated at the University of Michigan from May until December 1986. The mortality rate in patients $<70$ years of age with AMI treated with PTCA was $6 \%$ ( 12 of 200 ) vs $34 \%$ ( 12 of 35 ) in elderly patients ( $p<0.0001)$. PTCA was technically more difficult in the elderly patients: the primary success rate was 181 of $200(90 \%)$ in the younger patients compared with 25 of $35(66 \%)$ in patients $>70$ years of age $(p<0.001)$.

Repeat catheterization: Eighteen patients had repeat coronary arteriography performed during their hospital course. In addition, 4 patients had an emergency repeat catheterization performed for recurrent ischemia. All 4 patients were found to have an occluded infarct-related artery and 3 of these patients subsequently died.

Thus, 14 of $23(61 \%)$ surviving patients had repeat coronary angiograms performed before hospital discharge. Thirteen patients had a patent infarct-related artery and 1 patient had silent reocclusion. Of the 9 patients without repeat arteriography, 4 had bypass surgery, 2 had a negative exercise treadmill test and in 3 patients a clinical decision was made not to repeat catheterization.

Long-term follow-up: Of the 23 surviving patients, 22 (96\%) have been followed through May 1, 1988, and all patients have been followed for a minimum of 18 months. The mean follow-up is $28 \pm 12$ months. As Figure 2 illustrates, the vast preponderance of deaths occurred in the hospital. In the 23 patients discharged from the hospital, therc have becn 3 additional deaths in the subsequent follow-up period. One patient died 2 months post-AMI secondary to congestive heart failure. Two patients did well post-AMI but died suddenly at 19 and 26 months post-AMI. Of the 20 surviving patients, 14 are asymptomatic and 6 have class II angina.

\section{DISCUSSION}

Scant evidence exists regarding the role of PTCA in the elderly patient. In this study of emergency PTCA in elderly patients with evolving AMI, a higher mortality rate was demonstrated compared with historical control patients ( 34 vs $6 \%$ ) $<70$ years of age who were similarly treated. This higher mortality was associated with a high incidence of peri-AMI complications including 3 major peripheral vascular complications requiring vascular surgery. While acute PTCA in these elderly patients resulted in significant morbidity and mortality, the lack of a concurrent control group precludes making definitive conclusions rcgarding the benefit to risk ratio in such patients. Moreover, the group of patients in the present study was complicated, as evidenced by the $17 \%$ rate of cardiogenic shock at presentation.

Treatment of AMI in the elderly is a difficult problem. Norris et $\mathrm{al}^{1}$ reported a $42 \%$ in-hospital mortality in 212 patients $>70$ years of age hospitalized for AMI from 1967 to 1968 in Auckland, New Zealand. They developed a coronary prognostic index and found age to be the most important predictor of in-hospital mortality 
from AMI. Latting et $\mathrm{al}^{2}$ reported their experience with 175 patients age $\geq 70$ years admitted with AMI in Atlanta, Georgia, from 1971 to 1977. The in-hospital mortality rate in these patients was $32 \%$ compared with $8.2 \%$ in patients younger than 70 years. The leading cause of death in the elderly patients was cardiogenic shock.

The poor prognosis in elderly patients with AMI provided the impetus to treat these high risk patients with thrombolytic agents. The GISSI Trial showed no significant improvement in mortality in elderly patients treated with intravenous streptokinase. ${ }^{3}$ Over $1,200 \mathrm{pa}-$ tients $>75$ years of age were randomized to intravenous streptokinase or placebo. While there was a slight trend for reduced mortality in streptokinase-treated patients ( 29 vs $33 \%$ ), this was not statistically significant. Lew et al ${ }^{4}$ recently reported a 10 -fold higher in-hospital mortality rate for 24 patients 75 years or older with AMI. The elderly patients had a $33 \%$ mortality rate compared with $3 \%$ in the 96 patients younger than 75 years similarly trcatcd. All patients were treated with intravenous streptokinase within 3 hours of symptom onset. These problems with thrombolytic intervention suggest that a strategy that avoids the risks of bleeding complications may be particularly advantageous in the elderly population.

The poor in-hospital prognosis in our patients was related in part to technical difficulties with PTCA. The PTCA success rate in the elderly patients was only $66 \%$ compared with $90 \%$ in younger patients similarly treated at our institution. Several other recent studies in younger patients have also reported coronary angioplasty success rates of $801090 \%$ in the setling of AMI. ${ }^{5-12}$ Therefore, elderly patients not only have a poor prognosis on the basis of their increased age, but their vessels appear to be less amenable to PTCA. We examined a number of variables in an attempt to find predictors of in-hospital mortality in our patient population. As expected, age more than 75 years, cardiogenic shock and anterior infarction all tended to be associated with an increased mortality. Importantly, the only variable clearly predictive of mortality was the presence of an occluded vessel after PTCA.

The importance of a patent vessel after AMI has been shown in the Western Washington Trial. ${ }^{13} \mathrm{~A}$ recent report by Mathey et al ${ }^{14}$ has also documented a correlation between infarct artery patency and longterm survival. Our data also suggest that a patent infarct artery may be important for short-term survival in elderly patients with AMI.

While acute coronary angioplasty did not appear to have a favorable impact on in-hospital survival in elderly patients with AMI, these patients had a very low postdischarge mortality. In the first 6 months after hospital discharge, there was only 1 death in 23 patients (4\% mortality rate). At a mean follow-up of 28 months, there were only 3 deaths ( $13 \%$ mortality rate) in these elderly high risk patients. This compares very favorably with historical controls. In 60 patients more than 70 years of age discharged from the hospital, Beaune et al ${ }^{15}$ reported a $17 \%$ 6-month mortality. Rapaport et al ${ }^{16}$ followed 33 elderly patients after discharge from hospital after AMI and found a 40\% 1-year mortality rate. In the present study, we cannot exclude that emergency PTCA led to an acceleration of the in-hospital mortality, creating a false impression of a favorable long-term outlook.

This relatively benign prognosis following discharge after reperfusion therapy has been previously demonstrated in younger patients. Stack et $a 1^{8,9}$ have reported similarly low out-of-hospital 6- and 12-month mortality rates. In addition to a low mortality rate after infarction, these patients had very low morbidity after discharge. Of the surviving patients, 14 of $20(70 \%)$ are asymptomatic at a minimum 12-month follow-up and no patients have class III or IV angina symptoms.

\section{REFERENCES}

1. Norris RM, Caughey DE, Deeming LW, Mereer CJ Scott PJ Coronary prognostıc index for predictıng survival after recovery from acute myocardial infarction Lancet 1970,2 485-488.

2. Latung LA, Silverman SF Acute myocardial infarction in hospitalized patients over age 70 Am Heart $J 1980 \cdot 700 \cdot 311-318$

3. Gruppo Italiano per lo Studio della Streptochinasi nell'Infarto Mrocardico (GISSI) Effectiveness of intravenous thrombolytic treatment in acute myocardial infarction. Lancet 1985:1-397-401.

4. Lew AS, Hod H, Cercek B, Shah PK, Ganz W. Mortality and morbidity rate of pat1ents older and younger than 75 years with acute myocardial infarction treated with intravenous streptokinase Am J Cardol 1987,59.1-5

5. Meyer J, Merx W, Schmitz H, Erbel R, Kicsslich T, Dorr R, Lambertz H, Bethge C, Krebs W, Bardos P, Minale C, Messmer BJ, Effert S Percutaneous transluminal coronary angıoplasty immediately after intracoronary streptolysis of transmural myocardial infarction Circulation 1982,66.905-913

6. O'Neill W, Timmis G, Bourdillon P, La1 P, Ganghadarhan V, Walton J, Ramos R, Laufer N, Gordon S, Schork MA, Pitt B. A prospective randomized clinical trial of intracoronary streptokinase versus coronary angioplasty therapy of acute myocardial infarction. $N$ Engl $J$ Med 1986,314,812-828

7. Hartzler GO, Rutherford BD, McConahay DR, Johnson WL, McCallister BD, Gura GM, Conn RC, Crockett JE. Percutaneous transluminal coronary angioplasty with and without thrombolytic therapy for treatment of acute myocardial infarction. Am Heart J 1983,106:965-973.

8. Stack RS, Calıff RM, Hinohara T, Phillips HR, Pryor DB, Simonton CA, Carlson EB, Morris KG, Behar VS, Kong Y, Peter RH, Hlatky MA, O'Connor $\mathrm{CM}$, Mark DB. Survival and cardiac event rates in the first year after emergency coronary angioplasty for acute myocardial infarction. JACC 1988,11.1141-1149 9. Stack RS, O'Connor CM, Mark DB, Hinohara T, Phillips HIR, Lee MM, Ramirez NM, O'Callaghan WG, Simonton CA, Carlson EB, Morris KG, Behar VS, Kong Y, Peter RH, Califf RM. Coronary perfusion during acute myocardial infarction with a combined therapy of coronary angioplasty and high-dose intravenous streptokinase. Circulation 1988,77 151-161

10. Topol EJ, Califf RM, George BS, Kereiakes DJ, Abbottsmith CW, Candeli RJ, Lee KL, Pitt B, Stack RS, O'Neill WW A randomized trial of immediate versus delayed elective angioplasty after intravenous tissue plasminogen activator In acute myocardial infarction. $N$ Engl $J$ Med 1987;317 58I-588.

11. Rothbaum DA, Linnemeier TJ, I andin RJ, Steinmet7 EF, Hillis JS, Hallam CC, Noble RJ, See MR. Emergency percutaneous transluminal coronary angioplasty in acute myocardial infarction: a 3 year experience. JACC 1987;10 264272.

12. O'Nell WW, Topol EJ, Fung A, Bourdilion PDV, Nicklas IM, Walton J, Bates ER, Pitt B. Coronary angioplasty as therapy for acute myocardial infarction. Untversity of Michigan experience. Circulation 1987,76( suppl II) $\cdot I I-79-I I$. 87

13. Kennedy JW, Ritchie JL, Davis KB, Stadius ML, Maynard C, Fritz JK. The western Washington randomized trial of intracoronary streptokinase in acute myocardial infarction. $N$ Engl J Med 1985;312:1073 1078 .

14. Mathey DG, Schofer J, Shechan FH, Krebber HJ, Justen M, Rodewald G, Dodge HT, Bleifeld W. Improved survival up to 4 years after early coronary thrombolysis. Am J Cardiol 1988:61.524-529

15. Beaune J, Touboul P. Boissel JP, Delahaye JP. Quantitative assessment of myocardial infarction prognosts to 1 and 6 months from clinical data. Eur $J$ Cardiol 1978:8.629-647.

16. Rapaport $\mathbf{E}$, Remedios $P$. The high risk patıent after recovery from myocard1al infarction recogntion and management JACC 1983,1.391-400. 